\title{
Fixed point theorems for correspondences with properties weaker than lower semicontinuity
}

\author{
MONICA PATRICHE
}

\begin{abstract}
.
In this paper, we study existence of fixed points for correspondences having weak continuity properties. The obtained results extend or improve the corresponding results present in literature. We use continuous selection technique and also well-known KKM principle in order to establish our fixed point theorems.
\end{abstract}

\section{REFERENCES}

[1] Ansari, Q. H. and Yao, J.-C., A Fixed point theorem and its applications to a system of variational inequalities, Bull. Austral. Math. Soc., 59 (1999), 433-442

[2] Benahmed, S. and Azé, D., On fixed points of generalized set-valued contractions, Bull. Austral. Math. Soc., 81 (2010), 16-22

[3] Cianciaruso, F., Colao, V., Muglia, L. and Xu, H.-K., On an implicit hierarchical fixed point approach to variational inequalities, Bull. Austral. Math. Soc., 80 (2009), 117-124

[4] Deutsch, F. and Kenderov, P., Continuous selections and approximate selection for set-valued mappings and applications to metric projections, SIAM J. Math.Anal., 14 (1983) 185-194

[5] Hadži'c, O., Fixed point theorems in not necessarily locally convex topological vector spaces, in: Lecture Notes in Math., Vol. 948, Springer, Berlin, 1982, pp. 118-130

[6] Hadžíc, O., Fixed Point Theory in Topological Vector Spaces, Univ. of Novi Sad, Novi Sad, 1984, 337 pp.

[7] Kim, I. S. and Park, S., Almost fixed point theorems of the fort type, Indian J. Pure Appl. Math., 34 (2003), $765-771$

[8] Kim, J. H. and Park, S., Almost fixed point theorems of the Zima type, J. Korean Math. Soc., 41 (2004), 737-746

[9] Kim, W. K., Some applications of the Kakutani fixed point theorem, J. Math. Anal. Appl., 121 (1987), 119-122

[10] Kozlowski, W. M., Common fixed points for semigroups of pointwise Lipschitzian mappings in Banach spaces, Bull. Austral. Math. Soc., 84 (2011), 353-361

[11] Li, X. S. and Huang, N.-J., Strong convergence theorems for fixed points of pseudo-contractive semigroup, Bull. Austral. Math. Soc., 76 (2007), 441-452

[12] Park, S., The Knaster-Kuratowski-Mazurkiewicz theorem and almost fixed points, Topol. Methods Nonlinear Anal., Journal of the Juliusz Schauder Center, 16 (2000), 195-200

[13] Park, S., The KKM principle implies many fixed point theorems,Topology Appl., 135 (2004), 197-206

[14] Park, S., The KKM principle in abstract convex spaces: Equivalent formulations and applications, Nonlinear Anal., 73 (2010), 1028-1042

[15] Patriche, M., A new fixed-point theorem and its applications in the equilibrium theory, Fixed point theory $\mathbf{1}$ (2009),159-171

[16] Patriche, M., Fixed point theorems for nonconvex valued correspondences and applications in game theory, Fixed Point Theory 14 (2013), 435-446

[17] Patriche, M., Fixed point theorems and applications in theory of games, Fixed Point Theory, 15 (2014), 199-212

[18] Patriche, M., Equilibrium in games and competitive economies, The Publishing House of the Romanian Academy, Bucharest (2011)

[19] Petrusel, A., Multivalued operators and fixed points, Pure Math. Appl., 11 (2000), 361-368

[20] Petrusel, A. and Rus, I. A., Fixed point theory of multivalued operators on a set with two metrics, Fixed Point Theory 8 (2007), 97-104

Received: 25.09.2014; In revised form: 23.03.2015; Accepted: 31.03.2015

2010 Mathematics Subject Classification. 37C25, 47H10, 54H25.

Key words and phrases. Fixed point theorem, almost lower semicontinuity, local intersection property, transfer open-valued correspondences. 
[21] O'Regan D. and Agarwal, R. P., Fixed point theory for admissible multimaps defined on closed subsets of Fréchet spaces, J. Math. Anal. Appl., 277 (2003), 438-445

[22] Shih, M.-H. and Tan, K.-K., Covering theorems of convex sets related to fixed-point theorems, in "Nonlinear and Convex Analysis-Proc. in Honor of Ky Fan" (B-L. Lin and S. Simons, eds.), Marcel Dekker, New York, 1987, pp. 235-244

[23] $\mathrm{Wu}, \mathrm{X}$. and Shen, S., A further generalisation of Yannelis-Prabhakar's continuous selection theorem and its applications, J. Math. Anal. Appl., 197 (1996), 61-74

[24] Wu, J. and Liu, Y., New coincidence point theorems in continuous function spaces and applications, Bulletin of the Australian Mathematical Society, 80 (2009), 26-36

[25] Zheng, X., Approximate selection theorems and their applications, J. Math. Anal. Appl., 212 (1997), 88-97

DEPARTMENT OF MATHEMATICS

UNIVERSITY OF BUCHAREST

ACADEMIEI 14, 010014 BUCHAREST, ROMANIA

E-mail address: monica.patriche@yahoo.com 